\title{
Expected Return on Activities and Changes in Dental Care with COVID-19
}

\author{
Josué Júnior Araújo Pierote1, Renato Assis Machado², João Victor Frazão Câmara ${ }^{3}$, Luiz Alexandre \\ Maffei Sartinni Paulillo4
}

${ }^{1}$ School of Dentistry, Santo Amaro University, São Paulo, SP, Brazil.

${ }^{2}$ Craniofacial Anomalies Rehabilitation Hospital, University of São Paulo, Bauru, SP, Brazil.

${ }^{3}$ Department of Biological Sciences, Bauru School of Dentistry, University of São Paulo, Bauru, SP, Brazil.

${ }^{4}$ Department of Restorative Dentistry, Piracicaba School of Dentistry, Campinas State University, Piracicaba, SP, Brazil.

Corresponding author:

João Victor Frazão Câmara (D): https://orcid.org/0000-0002-9687-4401

E-mail: jvfrazao92@hotmail.com

Received: 31 July 2020 / Review: 19 August 2020 / Accepted: 28 August 2020

Dear Editor,

The novel coronavirus (COVID-19) has been spreading daily all over the world. Currently, more than 17,106,007 cases were positive for COVID-19 worldwide and 668,910 deaths (https://who.sprinklr.com). Besides that, few is known about this virus and what the real damage it can cause. The COVID-19 was identified in the saliva of infected patients, and this fluid can be pivotal in the transmission between humans. As a thought for dental clinics, many droplets and aerosols from saliva are expected, so that dental schools were closed, and dental clinics have been advised to maintain only urgency services around the world.

However, even after returning from activities, we will need to be very careful. Analysis of the Covid19 transmission projections will possibly require intermittent or prolonged isolation and social distancing measures until 2022 in the absence of an effective preventive measure. Even in periods of apparent pandemic control, monitoring must be maintained since the risk of a resurgence of new waves of spread and contamination may be possible until 2024 [1]. For this, the guideline below can be followed for reducing the exposition to COVID-19 in dental clinics:

1) Electronic apps and social media could be available to patients to initial screen patients, as recently described in oral medicine [2].

2) The consultation could be scheduled so as not to accumulate people in the waiting room, in addition to recommending patients to come to the consultation alone, if possible.

3) A container with $0.1 \%$ sodium hypochlorite can be used for patients and professionals to step on their shoes before entering the clinic, in addition to washing their hands or applying alcohol gel $62-71 \%$. 
4) After the patient come to the clinic, take temperature readings and have a rinse with $1 \%$ hydrogen peroxide or $0.2 \%$ povidone is recommended before each appointment. Chlorhexidine may not be effective [3].

5) Use personal protective equipment: masks, gloves, caps, lab coats, and shoe cover.

6) Autoclaving all instruments after each patient, including handpieces.

7) Keep the clinic room always clean, including door handles, chairs, and bathrooms. The surface disinfection procedures recommend the use of $62-71 \%$ ethanol, $0.5 \%$ hydrogen peroxide, or $0.1 \%$ sodium hypochlorite within 1 minute. Other biocidal agents such as $0.05-0.2 \%$ benzalkonium chloride or $0.02 \%$ chlorhexidine digluconate are less effective [4].

This simplified guide can help dental professionals and dental course coordinators to apply in their clinics, avoiding contagion and the contamination of the patients and other professionals at this moment and the return of activities.

\section{References}

[1] Kissler SM, Tedijanto C, Goldstein E, Grad YH, Lipsitch M. Projecting the transmission dynamics of SARS-CoV-2 through the postpandemic period. Science 2020; 368(6493):860-8. https://doi.org/10.1126/science.abb579

[2] Machado RA, de Souza NL, Oliveira RM, Júnior HM, Bonan PRF. Social Media and telemedicine for oral diagnosis and counselling in the COVID-19 Era. Oral Oncol 2020; 105:104685. https://doi.org/10.1016/j.oraloncology.2020.104685

[3] Peng X, Xu X, Li Y, Cheng L, Zhou X, Ren B. Transmission routes of 2019-nCoV and controls in dental practice. Int J Oral Sci 2020; 12(9):1-6.

[4] Kampf G, Todt D, Pfaender S, Steinmann E. Persistence of coronaviruses on inanimate surfaces and their inactivation with biocidal agents. J Hosp Infect 2020; 104(3):246-51. https://doi.org/10.1016/j.jhin.2020.01.022 